This item was submitted to Loughborough's Research Repository by the author.

Items in Figshare are protected by copyright, with all rights reserved, unless otherwise indicated.

\title{
Napping in high-performance athletes: Sleepiness or sleepability?
}

PLEASE CITE THE PUBLISHED VERSION

https://doi.org/10.1080/17461391.2020.1743765

PUBLISHER

Taylor and Francis

VERSION

AM (Accepted Manuscript)

PUBLISHER STATEMENT

This is an Accepted Manuscript of an article published by Taylor \& Francis in European Journal of Sport Science on 26 Mar 2020, available online: https://doi.org/10.1080/17461391.2020.1743765

\section{LICENCE}

CC BY-NC-ND 4.0

\section{REPOSITORY RECORD}

Gupta, Luke, Kevin Morgan, C North, and Sarah Gilchrist. 2020. "Napping in High-performance Athletes: Sleepiness or Sleepability?”. Loughborough University. https://hdl.handle.net/2134/12110766.v1. 


\title{
Napping in high-performance athletes: sleepiness or sleepability?
}

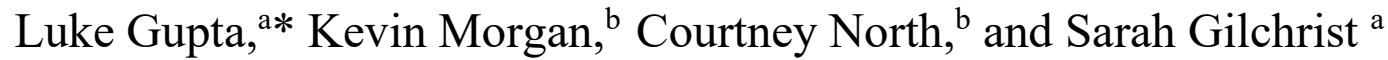

${ }^{a}$ The High Performance Centre, Bisham Abbey National Sports Centre,

Buckinghamshire SL7 1RR, UK and School of Sport, Exercise and Health Sciences, Loughborough University, Leicestershire LE11 3TU, UK; ${ }^{b}$ Clinical Sleep Research

Unit, School of Sport, Exercise and Health Sciences, Loughborough University, Leicestershire LE113TU, UK

*corresponding author

Luke Gupta

Senior Project Physiologist

The High Performance Centre,

Bisham Abbey National Sports Centre,

Buckinghamshire SL7 1RR, UK

Disclosure of interest.

The authors report no conflicts of interest.

Luke Gupta was supported in this research by a grant from the English Institute of Sport. 


\section{Napping in high-performance athletes: sleepiness or sleepability?}

Daytime napping is a common practice in high-performance athletes, and is widely assumed to reflect sleepiness arising from sports-related sleep debt. The possibility that athlete naps may also be indicative of 'sleepability', a capacity to nap on demand that is only weakly related to homeostatic sleep pressure, has not previously been tested. The present study compared daytime sleep latencies in high performance athletes and non-athlete controls using a single nap opportunity model. Elite $(\mathrm{n}=10)$, and sub-elite $(\mathrm{n}=10)$ athletes, and nonathlete controls $(\mathrm{n}=10)$ attended the laboratory for a first adaption trial, and a subsequent experimental trial. Subjective sleepiness was assessed using the Karolinska Sleepiness Scale (KSS) at 14.00, 14.30 and immediately prior to a 20minute nap opportunity at 15.00 . Sleep latencies were measured using polysomnography, and defined as the time from lights out to the first epoch of any stage of sleep (N1, N2, N3, REM). In unadjusted comparisons with non-athlete controls, elite athletes showed significantly shorter sleep latencies in both the adaptation $(p<0.05)$ and experimental trials $(p<0.05)$. These significant differences were maintained in models controlling for pre-trial KSS scores and pre-trial total sleep time $($ all $\mathrm{p}<0.05)$. Sleep latency scores for sub-elite athletes showed similar trends, but were more labile. These results are consistent with a conclusion that, among elite athletes, napping behaviour can reflect sleepability and may not necessarily result from nocturnal sleep disruption and daytime sleepiness.

Keywords: athlete; sleep; nap; sleepability; MSLT; arousal

\section{Introduction}

While the importance of nocturnal sleep for athlete performance and wellbeing is now widely recognized (Fullagar et al., 2015; Gupta, Morgan, \& Gilchrist, 2017; O’Donnell, Beaven, \& Driller, 2018b; Thun, Bjorvatn, Flo, Harris, \& Pallesen, 2015), the sports science literature also reflects a growing consensus around three aspects of daytime napping: that napping is a common practice in elite sport; that daytime naps can enhance sports performance; and that athlete naps result from (and therefore provide evidence of) sleep debt (see (Fullagar et al., 2015; O’Donnell et al., 2018b; Romyn et al., 2018). Support for the first two of these propositions comes directly from research evidence. Studies conducted among national squads, for example, report that $43 \%$ of junior (Kölling 
et al., 2016) and 48\% of senior (Sargent, Lastella, Halson, \& Roach, 2014) athletes nap during normal training. Regarding benefits, scheduled naps have been reported to significantly improve sprint times in healthy young males (Waterhouse, Atkinson, Edwards, \& Reilly, 2007) peak jump velocity in elite female netball players (O’Donnell, Beaven, \& Driller, 2018a), and cognitive performance in highly trained male athletes (Petit et al., 2018).

However, the assumption that napping is primarily due to increased homeostatic sleep pressure resulting from inadequate nocturnal sleep (e.g. (Davies, Graham, \& Chow, 2010; Lastella, Roach, Halson, \& Sargent, 2015; O’Donnell et al., 2018a; Petit, Mougin, Bourdin, Tio, \& Haffen, 2014; Romyn et al., 2018) is not well supported by empirical findings. In particular, studies evaluating relationships between athlete napping and subjective daytime sleepiness (the cardinal symptom of sleep debt) are lacking. This is an important omission since it is possible that, for some athletes, napping may not be compensatory. Broughton and Dinges (Broughton \& Dinges, 1989), for example, recognized 3 types of napping which differ in their relationship with daytime sleepiness: prophylactic napping (in anticipation of sleep loss); replacement or compensatory napping (in response to sleep loss); and appetitive napping (for convenience or enjoyment). In a factor-analytic study of napping typologies among young adults, Duggan et al (Duggan, McDevitt, Whitehurst, \& Mednick, 2018) found that appetitive napping 'on demand' was significantly associated with higher quality nocturnal sleep, and was not significantly associated with daytime sleepiness.

This ability to nap on demand has been termed 'sleepability' (Harrison \& Horne, 1996; J. Horne, 2010), and has been explored in Multiple Sleep Latency Tests (MSLTs) which use polysomnographic criteria to measure the time taken to fall asleep (sleep latency) when presented with a nap opportunity (Littner et al., 2005). While MSLT scores are responsive to changes in homeostatic sleep pressure (Arand et al., 2005), high sleepability has been identified in healthy young adults who record low MSLT scores (i.e. they tend to fall asleep quickly) independent of daytime sleepiness scores (Harrison \& Horne, 1996). Since napping behaviour is a common feature of high-performance sport spanning junior and senior levels, it is possible that athletes may develop a superior ability to sleep on demand during the day. Such a possibility could be tested by comparing the nap behaviour of appropriately matched athletes and non-athletes while controlling for levels of daytime sleepiness. To date, however, attention to athlete nap electrophysiology 
has not included comparison groups (e.g. (Petit et al., 2014; Romyn et al., 2018), and no study has explored the construct of 'sleepability' in athlete samples.

The present study, therefore, was designed to compare the daytime sleep tendencies of high-performance athletes and non-athlete controls using a single nap opportunity MSLT model involving 2 consecutive attendances at the laboratory: a first (adaptation) trial; and a second (experimental) trial. Adaptation periods are embedded in MSLT protocols (see Littner et al., 2005) in order to eliminate 'first night effects' (atypically disturbed sleep on first experiencing the sleep laboratory; (Agnew, Webb, \& Williams, 1966)). Initiating sleep in a novel environment is a common scenario among elite athletes, particularly during competitions (Erlacher, Ehrlenspiel, Adegbesan, \& El-Din, 2011; Juliff, Halson, \& Peiffer, 2015), and training camps (Pitchford et al., 2016). Given this, our adaptation trial served both to familiarize participants with the laboratory environment and simulate the challenge of sleeping in an unfamiliar setting, allowing the study to address the following research questions.

(1) In: i) novel; and ii) familiar environments, do high performance athletes show greater levels of daytime sleep tendency (as evidenced by shorter sleep latencies) when compared with non-athlete controls?

(2) If present, are differences in daytime sleep tendency between athletes and nonathletes primarily mediated by differences in daytime sleepiness?

Broadly, these questions involve the same null hypothesis: sleep tendency measures from a single-trial nap opportunity will show no significant differences between highperformance athletes and non-athlete control participants. To further explore whether napping behaviour is influenced by factors relating to the degree of athletic eliteness, 2 operationally defined groups of high-performance athletes were included, an elite group, and a sub-elite group.

\section{Methods}

\section{Participant selection}

Approval for the study was obtained from the Internal Review Board of the English Institute of Sport (EIS) and the Ethics Approvals (Human Participants) Sub-Committee of Loughborough University. Participants were recruited between the $1^{\text {st }}$ and $6^{\text {th }}$ weeks of Semester 2 (to avoid the examination timetable) from the Loughborough University 
student population using an electronic message-board requesting athlete and fit nonathlete volunteers for a study of night-time sleep quality and daytime sleep tendency. Prior to allocation volunteers completed:

(1) The Pittsburgh Sleep Quality Index (PSQI), a 19-item scale assessing sleep quality and sleep disturbances over the previous month. Scores range from 021 , with score $>5$ indicating poor sleepers (Buysse, Reynolds, Monk, Berman, \& Kupfer, 1989).

(2) The Ford Insomnia Response to Stress Test (FIRST), a 9-item scale which assesses sleep reactivity (i.e. how an individual's sleep responds when it is challenged or under stress). Scores range from 9-36 with scores $>18$ indicating individuals most likely to experience disturbed sleep under circumstances of challenge or stress ((Drake, Richardson, Roehrs, Scofield, \& Roth, 2004; Kalmbach, Vivekpillai, Toddarnedt, \& Drake, 2016).

(3) The Horne and Ostberg Morningness-Eveningness Questionnaire (MEQ), a 19item scale covering habitual rising and bedtimes, and preferred times of physical and mental performance, and subjective alertness after rising and before going to bed. Scores range from 16-86 with chronotype characterized as “evening”, "intermediate" or "morning” types (J. A. Horne \& Ostberg, 1976).

Following completion of the questionnaire assessments, Natale and Cicogna's (2002) classification schema was used to exclude those scoring <30 ("definitely evening types") or $>70$ ("definitely morning types") on the MEQ. Habitual sleep patterns were then screened over 7 consecutive days using Motionwatch 8 actigraphy (Camntech, Cambridge, UK), a valid instrument (Elbaz et al, 2012) showing reliability in field studies (Chakravarthy \& Resnick, (2017); Herbert et al, 2017). Epoch length was set at 30 seconds (Mode 3). Using these recordings, mean and standard deviation values for sleep latency (SL) and total sleep time (TST) were calculated for each individual. Those meeting research diagnostic criteria for insomnia symptoms (Edinger et al, 2004) by scoring $>5$ on the PSQI and recording 7-day averaged actigraphic sleep latencies $>30$ minutes were also excluded from the study; two volunteers were excluded on this basis. Selected volunteers were allocated to 1 of 3 groups using the following inclusion criteria. Elite athletes: currently competing at (at least) a national level and judged against Swann 
et al.'s (Swann, Moran, \& Piggott, 2015) taxonomy to be 'semi-elite' or 'competitive elite'. Sub-elite athletes: currently competing for the University, but below a national level of competition. Non-athlete controls: not engaged in competitive sport, non-obese and non-smokers/vapors, and meeting the WHO recommended levels of physical activity (i.e. $\geq 30$ minutes of moderate to vigorous physical activity performed daily on at least 5 days/week).

\section{Sample size}

Sample size was estimated using G*Power 3 (Faul, Erdfelder, Lang, \& Buchner, 2007), and was based on an effect size of 0.64 , calculated from sleep latency data reported in 2 studies in which participants and procedures approximated to the present design: Petit et al's (Petit et al., 2014) study of a single nap opportunity in athletes (mean sleep latency = 7.7 minutes; $\mathrm{SD}=3.9$ minutes), and Bonnet and Arand's (Bonnet \& Arand, 1998) study of MSLT performance in physically active young adults (baseline mean MSLT $=13.0$ minutes; SD 5 minutes). Setting alpha $=0.05$ and beta $=80 \%$, and assuming an effect size of 0.64, a 3-group F-test would require a minimum of 27 participants (9/group) with a critical F-value $=3.4$. Present recruitment achieved 10/group. Across the sub-elite and elite athlete groups, $81 \%$ of athletes represented endurance-based sports, mainly middleand long-distance running $(n=11)$, swimming $(n=4)$, and triathlon $(n=3)$; with the remaining representing team-sports.

\section{Sleep latency recordings}

Participants reported to the sleep laboratory at 13:30 on two consecutive occasions within one week (separated by a minimum of 3 days) for the adaptation trial and experimental trial respectively. Actigraphic measurements of sleep were obtained from all participants for the night immediately preceding both trials. All pre-trial TSTs were required to fall within 2 standard deviations of that individuals screening average. Trials consisted of a single nap opportunity at 15:00, selected due to the heightened level of sleep tendency associated with this time of day (Dijk, Groeger, Stanley, \& Deacon, 2010). The sleep laboratory maintained a regime of calm quietness; trials were conducted in complete darkness and rooms were maintained at $40-50 \%$ humidity and a temperature of $20-21^{\circ} \mathrm{C}$. Sleep latencies were measured using polysomnography (PSG; Embla Systems, Denver, CO, USA). The montage included: electroencephalography (EEG) - central (C3-A2, C4A1) and occipital (O1-A2, O2-A1); left and right eye electrooculograms (EOGs); and 
mental/submental electromyogram (EMG). Once electrodes were attached, and following standard bio-calibration procedures, participants were asked to "lie, assume a comfortable position, keep your eyes closed and try and fall asleep". According to American Academy of Sleep Medicine (American Academy of Sleep Medicine, 2005) criteria for MSLTs (Arand et al., 2005; Littner et al., 2005), sleep latency was measured as the time from lights out to the first epoch of any stage of sleep (N1, N2, N3, REM) (Silber et al., 2007). Sleep onset was, in turn, defined as the first epoch of greater than $15 \mathrm{sec}$ of cumulative sleep in a $30 \mathrm{sec}$ epoch. The absence of sleep on the nap opportunity was recorded as a sleep latency of 20 min. PSG traces were scored by two independent researchers, and concordance was assessed. Participants who scored $\leq 8 \mathrm{~min}$ were judged to have a 'high sleep tendency' according to AASM (American Academy of Sleep Medicine, 2005) criteria.

\section{Sleepiness assessment}

The Karolinska Sleepiness Scale (KSS) was administered at 14:00, 14:30, and immediately prior to the nap opportunity at 15:00. This 9-point verbally anchored Likert scale measures sleepiness (as subjective sleep tendency) in the 5 minutes preceding the rating. Scale scores range from 1, 'extremely alert', through 5 'neither alert nor sleepy', to 9, 'very sleepy, great effort to stay awake, fighting sleep' (Akerstedt \& Gillberg, 1990). The scale is sensitive to changes in homeostatic sleep pressure ( $\AA$ kerstedt, Anund, Axelsson, \& Kecklund, 2014) and has been used previously among elite athletes (McGuckin, Sinclair, Sealey, \& Bowman, 2014).

\section{Statistical analysis}

Pearson's correlation coefficient and Cohen's kappa were used to evaluate inter- and intra-rater reliability for the scoring of sleep latency and sleep onset respectively. Two measures of sleep tendency were used: i) sleep latency scores (in minutes); and ii) the proportions of those showing 'high sleep tendency' (i.e. sleep latency scores $\leq 8$ minutes) within the non-athlete, sub-elite athlete and elite athlete groups. Preliminary ANOVA modelling showed significant interactions between sleep latency scores and both KSS scores and pre-trial (actigraphy) TST scores, violating the assumption of homogeneity of regression slopes for ANCOVA. For the adaptation and experimental trials, therefore, sleep latency scores in the 3 groups were first compared in multiple regression models, 
with dummy codes designating non-athletes as the reference group and sub-elite and elite athlete groups as covariates (the unadjusted model). To directly address the experimental hypotheses this model was then repeated with either 15:00 KSS or pre-trial actigraphic TST scores separately added as covariates. In 2 further exploratory analyses, the model was repeated with PSQI global scores and subjective 'usual' TST (from the PSQI) separately added as covariates. Within all models differences between athlete group and reference means were determined using t-tests. Proportions categorized as 'high sleep tendency' within the 3 groups were compared using Fisher's Exact Test. To assess changes in pre-trial subjective sleepiness, KSS scores were compared in a two-way (group: non-athlete; sub-elite athlete; elite athlete $\mathrm{x}$ time: 14:00; 14:30; 15:00) repeated measures ANOVA. All statistics were performed using SPSS 23 for Windows (Version 23.0, SPSS inc., IBM, Armonk, New York).

\section{Results}

Participant characteristics are shown in Table 1. There were significant differences in training volume $(p<0.01)$ and estimated training energy expenditure $(p<0.001)$ between elite and sub-elite athletes. No other between-group comparisons showed significant differences. Sleep variables (mean \pm SD) for the nights immediately preceding the sleep latency trials are shown in Table 2. There were no significant between-group differences in total sleep (TST) or sleep onset latency (SOL).

\section{Sleep scoring reliability}

Inter-rater correlation coefficients for the first and second trial sleep latency scores were $0.83(\mathrm{p}<0.001)$ and $0.79(\mathrm{p}<0.001)$ respectively. The inter-rater Kappa coefficients for the identification of sleep onset within a nap was 0.7 for the adaptation trial and 0.9 for the experimental trial (both $\mathrm{p}<0.001$ ).

\section{Pre-trial sleepiness}

Karolinska Sleepiness Scale (KSS) scores prior to each sleep latency trial are shown in Figure 1. Two way (group $\mathrm{x}$ time) ANOVAs showed a significant main effect of time on subjective sleepiness prior to both the adaptation trial $\left(\mathrm{F}_{(2,54)}=35.51, \mathrm{p}<0.001\right)$ and the experimental trial $\left(\mathrm{F}_{(2,54)}=25.28 ; \mathrm{p}<0.001\right)$, with subjective sleepiness increasing significantly from 14:00 to 15:00 (Figure 1). A significant main effect for group was also present for the adaptation trial $\left(\mathrm{F}_{(2,27)}=4.49, \mathrm{p}=0.021\right)$, with paired comparisons showing greater overall sleepiness for sub-elite athletes relative to both the non- and the elite 
athletes. The experimental trial showed no main effect of group $\left(\mathrm{F}_{(2,27)}=0.96, \mathrm{p}=0.34\right)$, and neither trial showed a significant group $x$ time interaction effect (adaptation: $F_{(2,27)}=$ 2.23, $\mathrm{p}=0.18$; experimental: $\left.\mathrm{F}_{(2,27)}=2.28, \mathrm{p}=0.12\right)$.

\section{Sleep tendency measures}

For most participants (63\%) sleep latency scores declined between the adaptation and experimental trials. To assess the relationship between sleep reactivity and trial performance, Pearson product moment correlations between FIRST and sleep latency scores were calculated across all groups. While FIRST scores correlated significantly ( $\mathrm{r}$ $=0.45 ; \mathrm{n}=30 ; \mathrm{p}<0.05)$ for the adaptation trial, the experimental trial correlation was weaker and nonsignificant $(\mathrm{r}=0.33 ; \mathrm{n}=30 ; \mathrm{p}>0.05)$.

\section{Adaptation Trial}

Mean sleep latency scores for the adaptation trial are shown in Table 2 and Figure 2. For the unadjusted regression analysis the overall model significantly predicted $33 \%$ of the variance in adaptation sleep latency scores $\left(\mathrm{F}_{(2,27)}=6.72 ; \mathrm{p}=0.004\right)$, with paired comparisons showing that mean sleep latencies for both the elite (mean $=10.3 \mathrm{~min} ; \mathrm{t}=-$ $2.53 ; \mathrm{p}=0.02)$ and sub-elite (mean $=8.0 \mathrm{~min} ; \mathrm{t}=-3.60 ; \mathrm{p}=0.001)$ groups differed significantly from non-athlete control group values $($ mean $=16.3 \mathrm{~min})$. When 15:00 KSS scores and pre-trial TST scores were separately added to the regression as covariates, the models remained significant overall (KSS adjusted model: $F_{(3,26)}=4.32 ; p=0.013$; TST adjusted model: $\left.F_{(3,26)}=4.8231 \mathrm{p}=.008\right)$ with both elite and sub-elite values differing significantly from the control group control values (Table 2). This pattern of results was maintained in the exploratory analyses with elite athletes differing significantly from controls in both the global PSQI adjusted model $(\mathrm{t}=3.5 ; \mathrm{p}=0.002)$ and the 'usual' subjective TST adjusted model $(\mathrm{t}=2.36 ; \mathrm{p}=0.03)$. Levels of 'high sleep tendency' at adaptation showed a significant association with group (Table 2 ), with only $20 \%$ of nonathletes, but $80 \%$ of sub-elite athletes, and $50 \%$ of elite athletes recording a sleep latency of $\leq 8$ minutes (Fisher's Exact Test $=7.02, \mathrm{p}<0.03$ ).

\section{Experimental Trial}

Mean sleep latency scores for the experimental trial are shown in Table 2 and Figure 2. For the unadjusted regression the overall model significantly predicted $21 \%$ of the variance in experimental sleep latency scores $\left(\mathrm{F}_{(2,27)}=3.56 ; \mathrm{p}=0.04\right)$, with paired comparisons showing that mean sleep latencies for the elite group (mean $=7.9 \mathrm{~min}$; $\mathrm{t}=$ - 
$2.53 ; \mathrm{p}=0.02)$ differed significantly from non-athlete control group values (mean $=13.7$ min). For the sub-elite group in the unadjusted model, mean sleep latency scores (mean $=9.1 \mathrm{~min})$ were marginally non-significant when compared with control values $(\mathrm{t}=-2.01$; $\mathrm{p}=0.055$ ). In the adjusted regression (with pre-trial KSS scores added as a covariate), both elite $(\mathrm{t}=-2.52 ; \mathrm{p}=0.02)$ and sub-elite $(-2.08 ; \mathrm{p}<0.05)$ values differed significantly from control values, though the model overall was non-significant $\left(F_{(3,26)}=2.63 ; p=0.07\right)$. This pattern of results was maintained in the exploratory analyses with elite athletes differing significantly from controls in both the global PSQI adjusted model $(\mathrm{t}=3.36$; $\mathrm{p}=0.002)$ and the 'usual' subjective TST adjusted model $(\mathrm{t}=3.54 ; \mathrm{p}=0.002)$. Levels of 'high sleep tendency' for the experimental trial showed a significant gradient across the groups (Table 2 ), with $20 \%$ of non-athletes, $60 \%$ of sub-elite athletes, but $80 \%$ of elite athletes recording a sleep latency of $\leq 8$ minutes (Fisher's Exact Test $=7.67, p<0.04$ ).

\section{Discussion}

The present results allow for the rejection of the general null hypothesis in relation to both research questions. Relative to non-athlete controls, elite athletes showed significantly shorter sleep latencies and a significantly greater likelihood of achieving the threshold for 'high sleep tendency' in the unadjusted comparisons for the adaptation and experimental trials. Furthermore, across both trials adjusted comparisons showed that these significant differences in mean sleep latency were independent of pre-trial (15:00) sleepiness and total sleep time on the preceding night and, in the exploratory analyses, independent of pre-trial global PSQI scores and subjective 'usual' TST (from the PSQI). It is reasonable to conclude, then, that between-group differences in sleep latency were not primarily mediated by differences in experienced daytime sleepiness. A similar, though less consistent pattern of differences was found in the adjusted comparisons for the sub-elite group, which showed shorter sleep latencies independent of pre-trial sleepiness (Table 2) in both the adaption and experimental trials, but not independent of TST recorded on the night preceding the experimental trial.

Two broad and interconnected conclusions are supported by these findings. First, since the adjusted analyses of sleep latency scores indicated that athlete-control differences were maintained independent of pre-trial subjective sleepiness (and since sleepiness is the cardinal symptom of increased homeostatic sleep pressure), it is reasonable to conclude that the present study provides evidence of higher "sleepability", 
as characterized by Harrison and Horne (Harrison \& Horne, 1996), among highperforming athletes. For the elite group, this conclusion is also supported by the unadjusted analyses, where greater sleep tendency was demonstrated despite elite athletes showing significantly lower KSS scores (in the adaptation trial) or KSS scores equivalent to other groups (in the experimental trial). Second, accepting the explanatory value of the sleepability construct, the present findings suggest that daytime napping per se does not necessarily provide evidence of sleep debt or excessive daytime sleepiness in high performing athletes. The overall pattern of results also suggests a 'gradient' in the degree to which athlete napping appears to be disconnected from homeostatic sleep need, with sub-elite athletes showing only partial or intermediate levels of sleepability between the elite- and non-athlete groups.

The superior ability shown by elite athletes in the present study to initiate sleep in both novel and familiar environments merits further investigation. One plausible factor which could be influencing these findings concerns the influence and management of hyperarousal. Extensive research supports the view that hyperarousal, and consequent pre-sleep cognitive activity, is a major factor delaying sleep onset and initiating sleep dysfunction in insomnia disorder (Espie, Broomfield, MacMahon, Macphee, \& Taylor, 2006; Harvey, 2002; Riemann et al., 2010). The sleep latency scores recorded by the athletes in this study may therefore be indicative of either lower constitutional levels of hyperarousal, or a superior ability to manage (and mitigate) hyperarousal. Whether 'sleepability' (and possible arousal management) is a trait favoured by sport selection and training regimes, or is a strategic skill acquired by athletes to manage routine sleep challenges or optimize recovery, cannot be determined by the present results. However, exploring this phenomenon could have useful implications for both understanding and managing sleep in elite sport. While indicative of "sleepability" (Harrison and Horne, 1996) the capacity to initiate sleep 'on demand' for so-called "appetitive-naps" (Broughton \& Dinges, 1989) has also been linked to higher quality night-time sleep (Duggan et al, 2018). Again, the selection methods used here, which limited variation in sleep quality among participants, do not allow this possibility to be examined using the present data. Nevertheless, it remains an interesting and testable hypothesis that daytime napping among some athletes, instead of indicating sleep inadequacy, might actually be indicative of superior night-time sleep quality. 
Descriptive findings from the present study provide confidence in the ability of the design to adequately address the study research questions. Participant profiles (Table 1), together with the overall pattern of results, justify the selection procedures employed, and are consistent with the assumptions made in designing and executing this study. While participants showed similar sleep quality (PSQI), sleep reactivity (FIRST) and chronotype (MEQ) scores, differences in training volume and energy expenditure are consistent with the criteria used to differentiate the sub-elite athlete and elite athlete groups at recruitment. The high proportion of participants $(63 \%)$ showing a decline in sleep latency from the adaptation to the experimental trial, and the significant correlation between FIRST scores and adaptation (but not experimental trial) sleep latencies, are both consistent with a generalized 'first night' effect. Similarly, the significant main effect of time shown for subjective sleepiness (KSS scores) prior to both the adaptation and experimental trials, with sleepiness increasing steadily and significantly from 14.00, supports the selection of 15.00 as a time offering a realistic nap opportunity to all 3 groups, and emphasizes the sensitivity of the KSS sleepiness measure.

The limitations of the present study, which was designed and powered to address only specific questions, should also be recognized. Efforts to reduce intrinsic contributions to pre-trial sleepiness were made at the level of selection by screening for disordered night-time sleep. However, the significantly higher KSS scores for sub-elite athletes at the adaptation trial (Figure 1) suggest the influence of additional group-specific sources of sleepiness. It is relevant to note that prior training on the day of each trial was not controlled for. While it is possible that the duration and intensity of uncontrolled pretrial training could have differentially affected physiological sleep tendency in individuals, it is less clear how such an influence could be uniformly exerted across a single group of 10 athletes participating in a range of sports/events. It should be emphasized, however, that the influence of differential levels of sleep need, as expressed through daytime sleepiness, were controlled in the adjusted analyses.

As a relatively new finding with implications for athlete welfare and performance, additional studies of napping in elite sport which focus on homeostasis, sleep adequacy, and the dynamics of daytime napping seem justified. In future studies of the type reported here we would recommend extended periods of actigraphic pre-trial monitoring in order both to capture a detailed profile of athlete sleep and identify variations in sleep need. Future experimental manipulations of pre-trial sleep durations, using sleep-extension 
protocols, together with laboratory tests of vigilance, could also usefully explore the robustness and implications of the present findings.

Finally, it should also be acknowledged that the scale of the present study may have contributed to instability in the group mean values and reduced power in the experimental trials. While the relatively modest $n$-sizes certainly limited the number of covariates which could reasonably be entered in the regression, participant selection procedures resulted in a generally stable pattern of means across the two trials, with no major outliers. In addition, effect sizes (estimated from the unstandardized beta values) showed robust mean differences in unadjusted athlete-control values ranging from 4.7 minutes (experimental trial, sub-elite v controls) to 8 minutes (adaptation trial, sub-elite $\mathrm{v}$ controls), while Cohen's $\mathrm{f}^{2}$ for these models (calculated as $\mathrm{f}^{2}=\mathrm{r}^{2} /\left(1-\mathrm{r}^{2}\right)$ ) adjusted models indicated medium ( $\mathrm{f} 2 \geq 1.5$ ) to large ( $\mathrm{f} 2 \geq 3.5$ ) effect sizes.

The following 'take home' messages emerge from the present study. First, among high performance athletes, daytime napping may not be indicative of inadequate nighttime sleep. Where compromised athlete sleep quality is suspected, therefore, evidence from sources other than daytime sleep tendency should be sought. Second, the ability of elite athletes rapidly to adapt to novel sleeping environments represents a personal advantage during periods spent away from home (training camps, competitions, etc.). Identifying 'robust' athlete travellers, therefore, could help focus support staff attention on those athletes with more vulnerable sleep. Given the significant correlations achieved in the present study between FIRST scores and sleep latency scores in the adaptation trial $(\mathrm{r}=0.45 ; \mathrm{n}=30 ; \mathrm{p}<0.05)$ we would recommend the use of formal metrics to identify such vulnerability. Finally, given the clear relevance of assessing homeostatic drive in relation to sleep variables, we would recommend that future studies of athlete napping include valid and reliable measurements of daytime sleepiness.

In conclusion, this study describes two interlinked trials which investigated daytime physiological sleep tendency in elite-, sub-elite, and non-athletes in models controlling for pre-trial sleepiness. The results indicate that elite and sub-elite athletes exhibit greater physiological sleep tendency both in a novel environment and following adaptation. 


\section{References}

Agnew, H. W., Webb, W. B., \& Williams, R. L. (1966). The first night effect: an EEG study of sleep. Psychophysiology, 2(3), 263-266. https://doi.org/10.1111/j.14698986.1966.tb02650.x

Ainsworth, B. E., Haskell, W. L., Herrmann, S. D., Meckes, N., Bassett, D. R., TudorLocke, C., et al. (2011). 2011 Compendium of Physical Activities: A Second Update of Codes and MET Values. Medicine and Science in Sports and Exercise, 43(8), $1575-1581$.

Åkerstedt, T., Anund, A., Axelsson, J., \& Kecklund, G. (2014). Subjective sleepiness is a sensitive indicator of insufficient sleep and impaired waking function. Journal of Sleep Research, 23(3), 242-254. https://doi.org/10.1111/jsr.12158

Akerstedt, T., \& Gillberg, M. (1990). Subjective and objective sleepiness in the active individual. The International Journal of Neuroscience, 52(1-2), 29-37. Retrieved from http://www.ncbi.nlm.nih.gov/pubmed/2265922

American Academy of Sleep Medicine. (2005). International Classification of Sleep Disorders II: Diagnostic and Coding Manual. Diagnostic and Coding Manual. Retrieved from http://www.amazon.com/dp/0965722023\%5Cnhttp://www.esst.org/adds/ICSD.pdf

Arand, D., Bonnet, M., Hurwitz, T., Mitler, M., Rosa, R., \& Sangal, R. B. (2005). The clinical use of the MSLT and MWT. Sleep, 28(1), 123-144.

Bonnet, M. H., \& Arand, D. L. (1998). Sleepiness as measured by modified multiple sleep latency testing varies as a function of preceding activity. Sleep, 21(5), 477-83. Retrieved from http://www.ncbi.nlm.nih.gov/pubmed/9703587

Broughton, R. J., \& Dinges, D. F. (1989). Napping: a ubiquitous enigma. In R. . Broughton \& D. F. Dinges (Eds.), Sleep and Alertness: Chronobiological, Behavioural, and Medical Aspects of Napping (pp. 1-7). NY: Raven Press.

Buysse, D. J., Reynolds, C. F., Monk, T. H., Berman, S. R., \& Kupfer, D. J. (1989). The Pittsburgh sleep quality index: A new instrument for psychiatric practice and research. Psychiatry Research, 28(2), 193-213. https://doi.org/10.1016/0165- 
1781(89)90047-4

Chakravarthy, A., Resnick, b. (2017). Reliability and Validity Testing of the MotionWatch 8 in Older Adults. Journal of Nursing Measurement 25 (3): 549558.

Davies, D. J., Graham, K. S., \& Chow, C. M. (2010). The effect of prior endurance training on nap sleep patterns. International Journal of Sports Physiology and Performance, 5(1), 87-97. Retrieved from http://www.ncbi.nlm.nih.gov/pubmed/20308699

Dijk, D.-J., Groeger, J. A., Stanley, N., \& Deacon, S. (2010). Age-related reduction in daytime sleep propensity and nocturnal slow wave sleep. Sleep, 33(2), 211-23. Retrieved from http://www.ncbi.nlm.nih.gov/pubmed/20175405

Drake, C., Richardson, G., Roehrs, T., Scofield, H., \& Roth, T. (2004). Vulnerability to stress-related sleep disturbance and hyperarousal. Sleep, 27(2), 285-91. Retrieved from http://www.ncbi.nlm.nih.gov/pubmed/15124724

Duggan, K. A., McDevitt, E. A., Whitehurst, L. N., \& Mednick, S. C. (2018). To Nap, Perchance to DREAM: A Factor Analysis of College Students' Self-Reported Reasons for Napping. Behavioral Sleep Medicine, 16(2), 135-153. https://doi.org/10.1080/15402002.2016.1178115

Edinger, J. D., Bonnet, M. H., Bootzin, R. R., Doghramji, K., Dorsey, C. M., Espie, C. A., et al. (2004). Derivation of research diagnostic criteria for insomnia: Report of an American Academy of Sleep Medicine Work Group. Sleep, 27(8), 1567-1596

Elbaz, M., Yauy, K., Metlaine, A., Martoni, M., Leger, D. (2012). Validation of a new actigraph motion watch versus polysomnography on 70 healthy and suspected sleep-disordered subjects. Journal of Sleep Research 21 (Supplement 1): 218-218.

Erlacher, D., Ehrlenspiel, F., Adegbesan, O., \& El-Din, H. G. (2011). Sleep habits in German athletes before important competitions or games. Journal of Sports Sciences, 29(8), 859-66. https://doi.org/10.1080/02640414.2011.565782

Espie, C. A., Broomfield, N. M., MacMahon, K. M. A., Macphee, L. M., \& Taylor, L. M. (2006). The attention-intention-effort pathway in the development of 
psychophysiologic insomnia: a theoretical review. Sleep Medicine Reviews, 10(4), 215-45. https://doi.org/10.1016/j.smrv.2006.03.002

Faul, F., Erdfelder, E., Lang, A.-G., \& Buchner, A. (2007). G*Power 3: A flexible statistical power analysis program for the social, behavioral, and biomedical sciences. Behavior Research Methods, 39(2), 175-191. https://doi.org/10.3758/BF03193146

Fullagar, H., Skorski, S., Duffield, R., Hammes, D., Coutts, A. J., \& Meyer, T. (2015). Sleep and athletic performance: The effects of sleep loss on exercise performance, and physiological and cognitive responses to exercise. Sports Medicine. https://doi.org/10.1007/s40279-014-0260-0

Gupta, L., Morgan, K., \& Gilchrist, S. (2017). Does elite sport degrade sleep quality? A systematic review. Sports Medicine, 47(7), 1317-33. https://doi.org/10.1007/s40279-016-0650-6

Harrison, Y., \& Horne, J. A. (1996). "High sleepability without sleepiness". The ability to fall asleep rapidly without other signs of sleepiness. Neurophysiologie Clinique, 26(1), 15-20. https://doi.org/10.1016/0987-7053(96)81530-9

Harvey, A. G. (2002). A cognitive model of insomnia. Behaviour Research and Therapy, 40(8), 869-93. Retrieved from http://www.ncbi.nlm.nih.gov/pubmed/12186352

Herbert, V., Pratt, D., Emsley, R., Kyle, S.D. (2017). Predictors of Nightly SubjectiveObjective Sleep Discrepancy in Poor Sleepers over a Seven-Day Period Vanessa settings. Brain Sciences 7(3); 29; https://doi.org/10.3390/brainsci7030029.

Horne, J. (2010). Sleepiness as a need for sleep: When is enough, enough? Neuroscience \& Biobehavioral Reviews, 34(1), 108-118. https://doi.org/10.1016/j.neubiorev.2009.07.009

Horne, J. A., \& Ostberg, O. (1976). A self-assessment questionnaire to determine morningness-eveningness in human circadian rhythms. International Journal of $\begin{array}{lllll}\text { Chronobiology, } & 4(2), & 97-110 . & \text { Retrieved }\end{array}$ http://www.ncbi.nlm.nih.gov/pubmed/1027738

Juliff, L. E., Halson, S. L., \& Peiffer, J. J. (2015). Understanding sleep disturbance in athletes prior to important competitions. Journal of Science and Medicine in Sport, 
18(1), 13-18. https://doi.org/10.1016/j.jsams.2014.02.007

Kalmbach, Vivekpillai, J., Toddarnedt, C., \& Drake, C. . (2016). Identifying at-risk individuals for insomnia using the Ford Insomnia Response to Stress Test. SLEEP, 39(2). https://doi.org/10.5665/sleep.5462

Kölling, S., Steinacker, J. M., Endler, S., Ferrauti, A., Meyer, T., \& Kellmann, M. (2016). The longer the better: Sleep-wake patterns during preparation of the World Rowing Junior Championships. Chronobiology International, 33(1), 73-84. https://doi.org/10.3109/07420528.2015.1118384

Lastella, M., Roach, G. D., Halson, S. L., \& Sargent, C. (2015). Sleep/wake behaviours of elite athletes from individual and team sports. European Journal of Sport Science, 15(2), 94-100. https://doi.org/10.1080/17461391.2014.932016

Littner, M. R., Kushida, C., Wise, M., Davila, D. G., Morgenthaler, T., Lee-Chiong, T., ... Standards of Practice Committee of the American Academy of Sleep Medicine. (2005). Practice parameters for clinical use of the multiple sleep latency test and the maintenance of wakefulness test. Sleep, 28(1), 113-21. Retrieved from http://www.ncbi.nlm.nih.gov/pubmed/15700727

McGuckin, T. A., Sinclair, W. H., Sealey, R. M., \& Bowman, P. (2014). The effects of air travel on performance measures of elite Australian rugby league players. European Journal of Sport Science, 14(sup1), S116-S122. https://doi.org/10.1080/17461391.2011.654270

Natale, V., \& Cicogna, P. (2002). Morningness-eveningness dimension: is it really a continuum? Personality and Individual Differences, 32(5), 809-816. https://doi.org/10.1016/S0191-8869(01)00085-X

O’Donnell, S., Beaven, C. M., \& Driller, M. (2018a). The Influence of Match-Day Napping in Elite Female Netball Athletes. International Journal of Sports Physiology and Performance, 13(9), 1143-1148. https://doi.org/10.1123/ijspp.2017-0793

O’Donnell, S., Beaven, C. M., \& Driller, M. W. (2018b). From pillow to podium: a review on understanding sleep for elite athletes. Nature and Science of Sleep, 10, 243-253. https://doi.org/10.2147/NSS.S158598 
Petit, E., Bourdin, H., Tio, G., Yenil, O., Haffen, E., \& Mougin, F. (2018). Effects of a 20-Min Nap Post Normal and Jet Lag Conditions on P300 Components in Athletes. International Journal of Sports Medicine, 39(07), 508-516. https://doi.org/10.1055/a-0599-0888

Petit, E., Mougin, F., Bourdin, H., Tio, G., \& Haffen, E. (2014). A 20-min nap in athletes changes subsequent sleep architecture but does not alter physical performances after normal sleep or 5-h phase-advance conditions. European Journal of Applied Physiology, 114(2), 305-315. https://doi.org/10.1007/s00421-013-2776-7

Pitchford, N. W., Robertson, S. J., Sargent, C., Cordy, Fj., Bishop, D. J., \& Bartlett, J. D. (2016). A Change in Training Environment Alters Sleep Quality But Not Quantity in Elite Australian Rules Football Players. International Journal of Sports Physiology and Performance, 1-18. https://doi.org/10.1123/ijspp.2016-0009

Riemann, D., Spiegelhalder, K., Feige, B., Voderholzer, U., Berger, M., Perlis, M., \& Nissen, C. (2010). The hyperarousal model of insomnia: A review of the concept and its evidence. Sleep Medicine Reviews, 14(1), 19-31. https://doi.org/10.1016/j.smrv.2009.04.002

Romyn, G., Lastella, M., Miller, D. J., Versey, N. G., Roach, G. D., \& Sargent, C. (2018). Daytime naps can be used to supplement night-time sleep in athletes. Chronobiology International, 35(6), 865-868. https://doi.org/10.1080/07420528.2018.1466795

Sargent, C., Lastella, M., Halson, S., \& Roach, G. (2014). The impact of training schedules on the sleep and fatigue of elite athletes. Chronobiology International, 31(10), 1160-8. https://doi.org/10.3109/07420528.2014.957306

Silber, M. H., Ancoli-Israel, S., Bonnet, M. H., Chokroverty, S., Grigg-Damberger, M. M., Hirshkowitz, M., ... Iber, C. (2007, March 15). The visual scoring of sleep in adults. Journal of Clinical Sleep Medicine. Retrieved from http://www.ncbi.nlm.nih.gov/pubmed/17557422

Swann, C., Moran, A., \& Piggott, D. (2015). Defining elite athletes: Issues in the study of expert performance in sport psychology. Psychology of Sport and Exercise, 16, 3-14. https://doi.org/10.1016/j.psychsport.2014.07.004

Thun, E., Bjorvatn, B., Flo, E., Harris, A., \& Pallesen, S. (2015). Sleep, circadian rhythms, 
and athletic performance. Sleep Medicine Reviews, 23, 1-9. https://doi.org/10.1016/j.smrv.2014.11.003

Waterhouse, J., Atkinson, G., Edwards, B., \& Reilly, T. (2007). The role of a short postlunch nap in improving cognitive, motor, and sprint performance in participants with partial sleep deprivation. Journal of Sports Sciences, 25(14), 1557-66. https://doi.org/10.1080/02640410701244983 
Table 1. Participant characteristics

\begin{tabular}{|c|c|c|c|c|}
\hline & $\begin{array}{l}\text { Non-athletes } \\
\qquad(n=10)\end{array}$ & $\begin{array}{l}\text { Sub-elite } \\
\text { athletes } \\
(n=10)\end{array}$ & $\begin{array}{l}\text { Elite athletes } \\
\qquad(\mathbf{n}=\mathbf{1 0})\end{array}$ & $\mathbf{P}^{*}$ \\
\hline Age (y) & $21.0 \pm 1.5$ & $22.8 \pm 4.8$ & $23.1 \pm 3.8$ & $p=0.63$ \\
\hline Female (\%) & $50 \%$ & $60 \%$ & $30 \%$ & $\mathrm{p}=0.53^{\mathrm{a}}$ \\
\hline \multicolumn{5}{|l|}{ Training: mean (SD) } \\
\hline Training volume: $\mathrm{h} / \mathrm{w}$ & NA & $9(4.0)$ & $17(7.0)$ & $\mathrm{p}<0.01$ \\
\hline Sport EE: METs ${ }^{b}$ & NA & $9.8(1.0)$ & $8.5(1.0)$ & $\mathrm{p}=0.23$ \\
\hline $\begin{array}{l}\text { Training EE: } \\
\text { METs/w } w^{b}\end{array}$ & NA & $91(47.0)$ & $156(91.0)$ & $\mathrm{p}<0.001$ \\
\hline \multicolumn{5}{|c|}{ Questionnaire sleep assessments: mean (SD) } \\
\hline FIRST & $20.2(4.9)$ & $17.4(3.7)$ & $16.7(4.6)$ & $\mathrm{p}=0.20$ \\
\hline PSQI & $3.9(1.3)$ & $4.6(2.1)$ & $5.5(0.2)$ & $\mathrm{p}=0.19$ \\
\hline MEQ & $51.9(10.1)$ & $55.5(12.6)$ & $52.6(9.1)$ & $\mathrm{p}=0.73$ \\
\hline \multicolumn{5}{|c|}{ 7-day actigraphic TST from screening: mean (SD) } \\
\hline TST: hours & $7.1(0.8)$ & $6.6(0.6)$ & $6.4(0.8)$ & $\mathrm{p}=0.10$ \\
\hline SL: minutes & $15.8(12.0)$ & $9.9(11.2)$ & $17.0(16.5)$ & $\mathrm{p}=0.46$ \\
\hline $\begin{array}{l}\text { *Probability of } \mathrm{F} \text { from on } \\
\text { Square; }{ }^{\mathrm{b}} \mathrm{MET} \text { s for each } \\
\text { Abbreviations: SD, stand } \\
\text { Test; PSQI, Pittsburgh Sl } \\
\text { Questionnaire; TST, total }\end{array}$ & $\begin{array}{l}\text { way ANOVA } \\
\text { lete's sport de } \\
\text { d deviation; FII } \\
\text { p Quality Indes } \\
\text { leep time; SL, s }\end{array}$ & $\begin{array}{l}\text { nless stated oth } \\
\text { ived from Ains } \\
\text { ST, Ford Inson } \\
\text {; MEQ, Mornir } \\
\text { eep latency. }\end{array}$ & $\begin{array}{l}\text { rwise; }{ }^{\text {a Pearson }} \\
\text { orth et al. ( } 2011 \\
\text { aia Response to } \\
\text { ness-Eveningne }\end{array}$ & $\begin{array}{l}\text { Chi } \\
\text { Stress } \\
\text { ss }\end{array}$ \\
\hline
\end{tabular}


Adaptation trial

$\begin{array}{cccccc}\text { Non- } & \text { Sub-elite } & \text { Elite } & \text { Non- } & \text { Sub-elite } & \text { Elite } \\ \text { athletes } & \text { athletes } & \text { athletes } & \text { athletes } & \text { athletes } & \text { athletes } \\ (n=10) & (n=10) & (n=10) & (n=10) & (n=10) & (n=10)\end{array}$

Pre-trial sleep assessment: mean (SD)

\begin{tabular}{|c|c|c|c|c|c|c|c|}
\hline Mean TST (hours) & $6.8(0.9)$ & $6.8(0.9)$ & $6.8(1.6)$ & $0.99^{1}$ & $7.1(1.4)$ & $6.4(1.3)$ & $6.5(0.9)$ \\
\hline Mean SL (minutes) & $16.2(19.4)$ & $9.8(17.4)$ & $14.7(16.1)$ & $0.70^{1}$ & $16.3(18.5)$ & $5.4(9.3)$ & $17.3(20.7)$ \\
\hline Mean $(15: 00)$ KSS scores & $5.7(0.8)$ & $6.6(0.95)$ & $5.1(1.3)$ & $0.05^{1}$ & $5.5(1.5)$ & $5.8(1.4)$ & $5.5(1.3)$ \\
\hline
\end{tabular}

Unadjusted trial outcomes

Mean sleep latency scores

in minutes: mean (SD)

$10.4(5.8)$

$<0.01^{1} \quad 13.7(5.8)$

$9.1(4.9)$

$7.9(4.8)$

$<0.05^{1}$

High sleep tendency

ratings: $\mathrm{n}(\%)$

$2(13.3 \%)$

$8(53.3 \%)$

$5(33.3 \%)$

$<0.05^{2} \quad 2(12.5 \%)$

$6(37.5 \%)$

$<0.05^{2}$ 


\begin{tabular}{|c|c|c|c|c|}
\hline Sleep latency scores & -8.3 & -5.9 & -4.8 & -5.9 \\
\hline adjusted for 15:00 KSS & $(-13.3,-3.2)$ & $(-11.0,-0.9)$ & $(9.6,0.05)$ & $(10.6,1.08)$ \\
\hline scores* & $<0.01^{3}$ & $<0.05^{3}$ & $<0.05^{3}$ & $<0.05^{3}$ \\
\hline Sleep latency scores & -8.3 & -5.9 & -4.5 & -5.8 \\
\hline adjusted for pre-trial TST & $(-13.2,-3.4)$ & $(-10.8,-1.1)$ & $(-9.5,-0.5)$ & $(-10.7,-0.8)$ \\
\hline scores* & $<0.01^{3}$ & $<0.05^{3}$ & $0.07^{3}$ & $<0.053^{3}$ \\
\hline
\end{tabular}

Notes ${ }^{1}$ significance of $\mathrm{F}$ for one-way ANOVA; ${ }^{2}$ significance of Fisher's Exact Test; ${ }^{3}$ Significance of control group v athlete group t-value. SD, standard deviation; TST, total sleep time; SL, sleep latency; KSS, Karolinska Sleepiness Scale (higher scores = greater subjective sleepiness). *Values are mean differences (95\% confidence intervals) between athlete groups and reference (non-athlete) values; negative signs indicate lower sleep latency scores for athlete groups. 

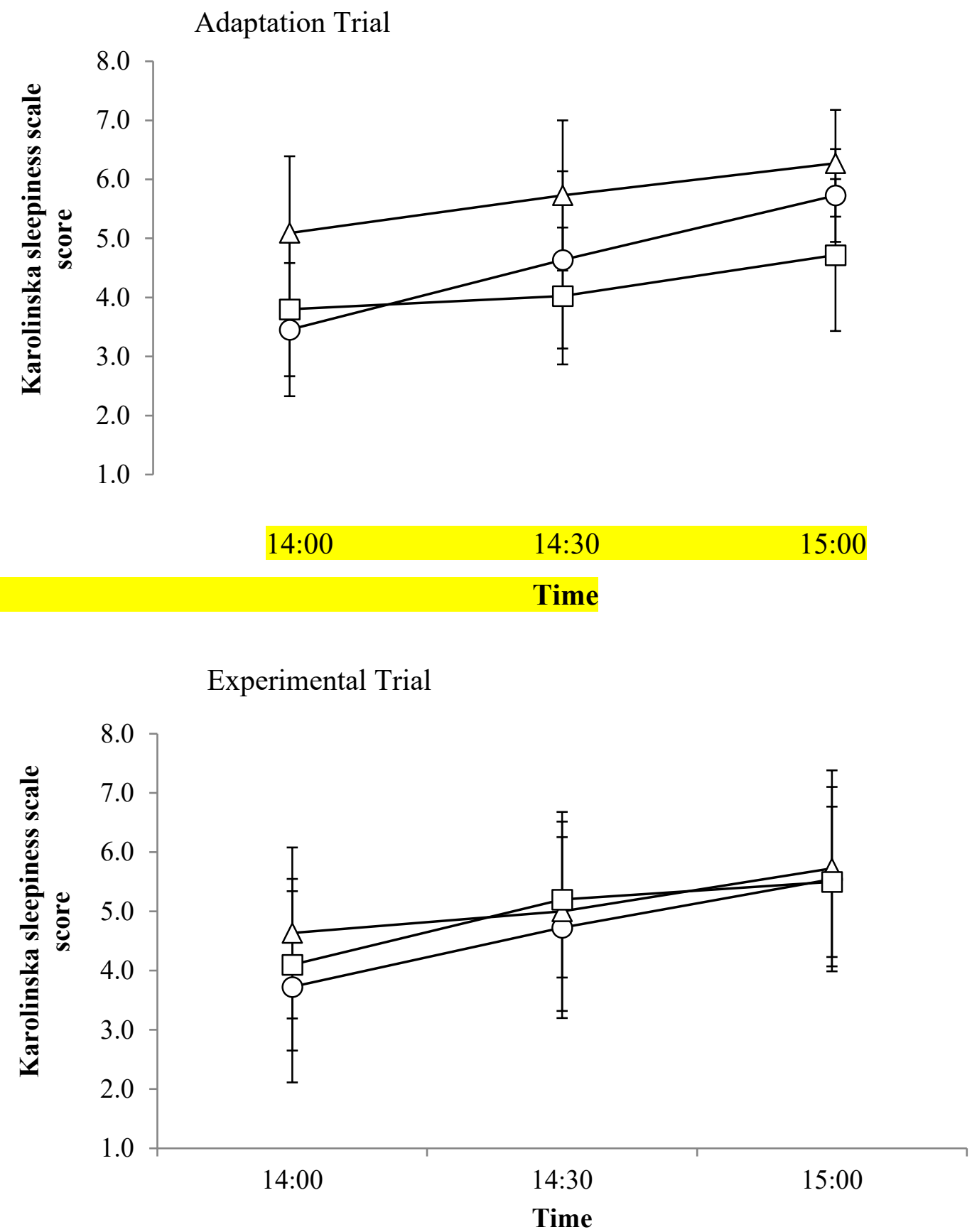

Figure 1. Mean Karolinska Sleepiness Scale (KSS) scores for non-athletes (O) sub-elite athletes $(\Delta)$ and elite athletes $(\square)$ prior to: the adaptation trial (above); and the experimental trial (below). Bars indicate 1 standard deviation. 

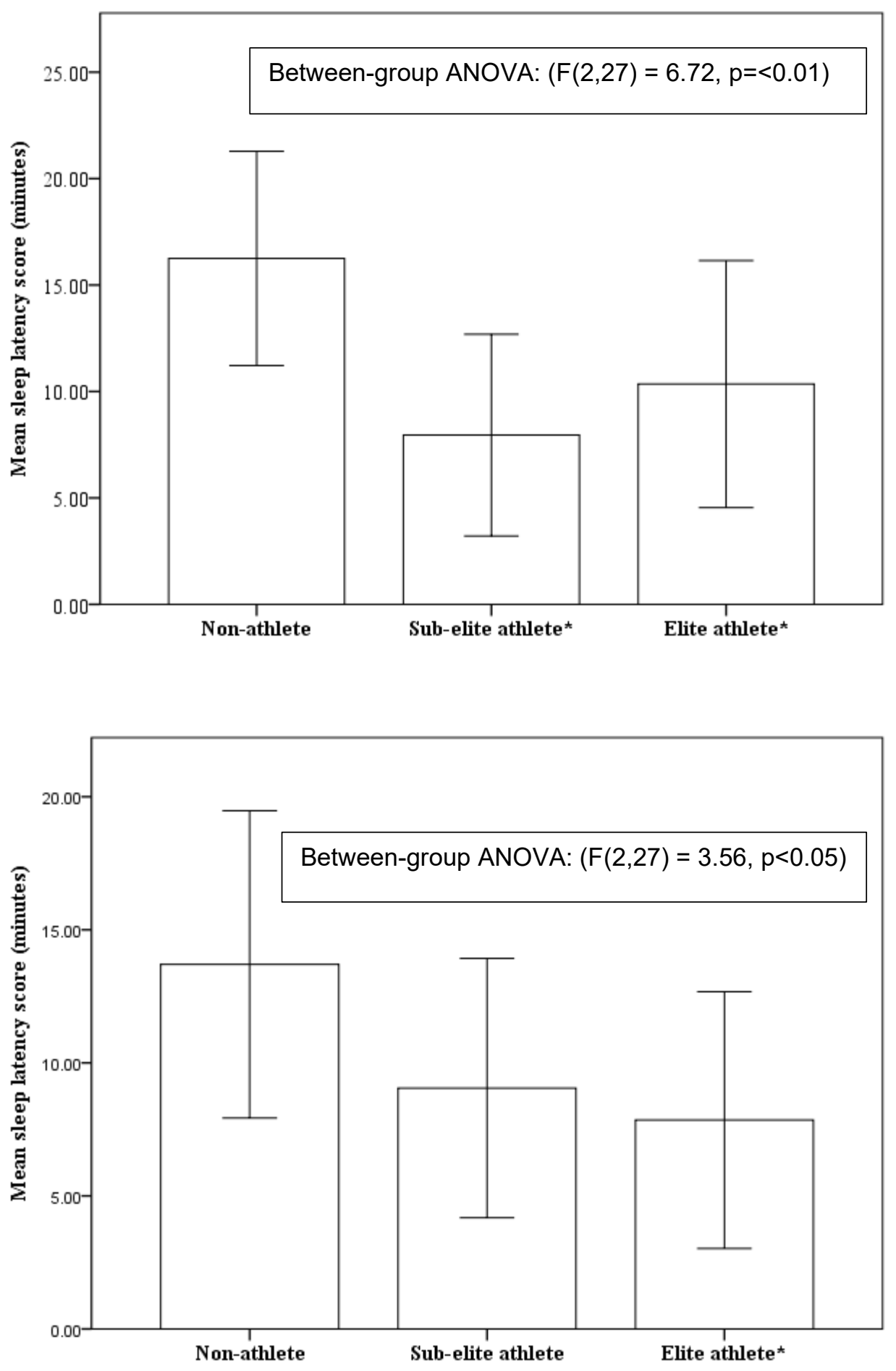

Figure 2. Mean adaptation trial (above) and experimental trial (below) sleep latency scores for a single nap opportunity $(\mathrm{n}=10$ /group). Bars indicate 1 standard deviation.

* significantly different from non-athlete $(p<0.05)$ 